\title{
O JORNALISMO NA ERA DIGITAL E AS FAKE NEWS
}

\author{
Gustavo Haiden de Lacerda ${ }^{\mathrm{a}}$ \\ Luciana Cristina Ferreira Dias Di Raimo
}

\begin{abstract}
RESUMO
Neste artigo, apresentamos uma reflexão a respeito do jornalismo e da prática de fake news, relacionando-os pelo aparato digital, a fim de problematizar os efeitos de verdade produzidos no discurso. Com base nos procedimentos teórico-metodológicos da Análise de Discurso de tradição francesa, foi possível entender melhor a relação do sujeito com a produção de notícias falsas pela discursividade digital.
\end{abstract}

PALAVRAS-CHAVE: imprensa; jornalismo digital; notícias falsas.

Recebido em: 22/03/19

Aprovado em: 03/10/19

\section{Delinear inicial}

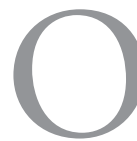

jornalismo posto em prática atualmente já não é mais o mesmo daquele praticado há alguns anos. As condições de produção são outras, os meios de circulação são outros, as vozes, os acontecimentos, os sujeitos, os sentidos, todos são outros, em função de um mundo afetado pela discursividade digital. Essas mudanças tiveram consequências sobre a prática

a Graduando em Letras (UEM) e bolsista de iniciação científica (CNPq).

b Doutora em Linguística Aplicada (Unicamp) e docente do Departamento de Língua Portuguesa da Universidade Estadual de Maringá (UEM). 
jornalística, e é isso que pretendemos discutir neste artigo. De modo particular, interessa-nos refletir sobre como o percurso do jornalismo o leva a constituir-se enquanto transmissor de "fatos verdadeiros" e como essa posição vem sendo desafiada pela prática de fake news no meio digital.

Para isso, subdividimos este texto em três partes. A primeira encarrega-se de traçar um contorno para a produção jornalística brasileira, até constituirse como instituição de divulgação da "verdade", função esta que deverá ser problematizada. Feito isso, apresentamos alguns pontos de reflexão sobre o jornalismo que se pratica atualmente, qual seja, um jornalismo digital, na tentativa de pensar como a materialidade digital significa a prática jornalística, mais especificamente as implicaçôes da relação dos sujeitos com a produção e a divulgação de textos on-line, elaborando algo como um "jornalismo alternativo". Por fim, em vista desse cenário, propomos a análise de uma notícia falsa que circulou nas redes sociais em 2018, a respeito de uma pesquisa eleitoral do mesmo ano que apontava, supostamente, que as votaçóes já seriam decididas em primeiro turno. Por meio desse percurso analítico, constatamos que tanto o discurso jornalístico quanto as fake news comungam de um desejo de verdade e são ambos afetados pelas ilusões discursivas, em que as fake news se serviriam do próprio imaginário de credibilidade do jornalismo para forjar uma posição jornalística para divulgar "sentidos falsos", que se debatem na textualidade da notícia falsa, produzindo dispersão e desinformação.

Não podemos perder de vista a filiação teórica que ancora nossas reflexôes: a Análise de Discurso de matriz pêcheuxtiana $(\mathrm{AD})$. Filiar-se à $\mathrm{AD}$ implica colocar-se numa posição que tome a língua na sua "autonomia relativa" (PÊCHEUX, 1995, p. 91), o que, em outras palavras, significa considerá-la como um sistema aberto à falha, suscetível ao equívoco, quando de sua inscrição na história. Na relação língua-história é que se produz o discurso, e é sobre essa relação que nos interessa pensar.

\section{A prática jornalística: um discurso sobre a imprensa}

A imprensa é fundada no Brasil no início do século XIX, com a vinda da família real para o país, em 1808, uma vez que ela se interessava em saber o que estava acontecendo em Portugal. Antes disso, leis de censura já haviam 
fechado tipografias que tentaram espaço em algumas regióes do país, além de impedirem e limitarem a circulação de diversos livros pelo território brasileiro. Conforme Mariani (1996), já aí começa a formar-se um quadro de funcionamento da instituição jornalística, marcada tanto por uma relação submissa ao poder vigente, no intuito de divulgar os ideais de uma elite e combater os movimentos contrários, quanto por constituir-se em torno de uma política de silêncio, isto é, de censuras. Fica postulado, assim, segundo Mariani (1996), que a imprensa é a instituição que organiza e faz circular os sentidos que são possíveis, ou melhor, os sentidos que são permitidos.

Por outro lado, Mariani (1996) chama-nos a atenção para o fato de que a memória discursiva atua sobre a imprensa, apagando o lugar de interpretação que a fundamenta e produzindo um efeito ideológico de evidência, que faz esquecer que ela opera na manutenção de um status quo, tornando os fatos desejáveis visíveis e silenciando aqueles indesejáveis, ou seja, (re)produzindo o mesmo sentido, regulado pelas relações de poder dominantes. Sendo assim, a imprensa passa a ser, em maior ou menor grau, dependendo do jornal, uma extensão do poder vigente. Há um já-dito sobre o jornalismo que o assujeita às exigências de outras instituições, como o Estado, a Igreja, o Mercado etc. O resultado é "a ilusão do jornalismo-verdade, [...] a ilusão de que os jornais são apenas testemunhas, meios de comunicação ou veículos informativos” (MARIANI, 1996, p. 88).

Por isso, na visão discursiva, não buscamos "verdade" nos fatos, mas indagamo-nos sobre como diferentes versóes produzem sentido, sem deixar de considerar que, no discurso, são produzidos efeitos de verdade. Esses "efeitos de verdade" na imprensa são elaborados em torno do discurso de objetividade construído pela instituição, que se coloca como canal "neutro" entre o mundo e o sujeito-leitor. A mídia trabalha no silenciamento de sua função mediadora (e, portanto, reguladora), esquecendo-se de que o sentido náo faz sentido longe do sujeito.

Desse modo, compreendendo as evidências do sujeito e do sentido como trabalho da ideologia e como processo de interpelação (nunca completo ou total) que pode abrir-se para falhas, Pêcheux (1995) apresenta e explica os esquecimentos discursivos: o primeiro de caráter inconsciente, da ordem da ideologia, que cria para o sujeito a ilusão de ele ser a origem dos sentidos que 
produz, e o segundo esquecimento, pré-consciente, da ordem da enunciação, responsável pelo efeito de literalidade, pelo qual o sentido seria uno e inequívoco, sobre o qual o sujeito teria pleno controle, uma vez que se veria livre para escolher suas palavras ao bel-prazer de suas intençóes. Porém, para a AD, a intenção nunca está distante das injunçóes e demandas sociais; pelo contrário, o sentido existe na história e não "colado" às palavras.

Afetada por esses dois esquecimentos, a imprensa toma para si a função de narrar os fatos na ilusão de objetividade, imparcialidade e comprometimento com a verdade, criando a impressão, pelo discurso, de que o que ocorreu só pode significar daquele modo, do modo como a imprensa o textualizou. $\mathrm{O}$ efeito de verdade é produzido por meio de estratégias que levam o leitor a assumir como legítimo esse imaginário construído pelo jornal e a se reconhecer nele. Dito de outro modo,

a prática discursiva jornalística está determinada tanto pela ilusão referencial da linguagem quanto por seu próprio processo histórico de constituição, o que supóe/impóe que os jornais podem e devem ser objetivos e imparciais. Ou seja, o que é especifico do discurso jornalístico, tal como o estamos concebendo, é ser cego aos efeitos inscritos no seu processo de produção/reprodução/transformação de realidades (MARIANI, 1996, p. 237).

Com isso, chegamos ao ponto em que verdade e informação se confundem na prática jornalística. O poder do jornal está edificado em torno do valor criado para a informaçáo. Sob o lema do "você precisa se informar", torna-se "evidente" (e injuntivo) para o sujeito que ele deve buscar informação e fará isso lendo ou assistindo a um jornal. No entendimento de Nunes (2012), o termo "informação" circula pela sociedade como evidência, silenciando sua transitividade, isto é, "informar o quêe?", reforçando a ideia de que a língua seria um mero instrumento de comunicação para transmitir informaçóes. Consequentemente, a informação é tornada produto de consumo, ou seja, "quanto mais se puder 'adquirir' informação, tanto melhor! O excesso (da informação) determinando sua falta (do conhecimento)" (NUNES, 2012, p. 34). 
Do modo como estamos pensando a informação, pelas lentes da $\mathrm{AD}$, é essencial que a evidência da informação seja desfeita. Nas palavras de Nunes (2012), o discurso que sustenta a prática informativa repete (para si e para os outros) que "sendo a falta (de informaçóes) constitutiva do sujeito seria necessária a produção de informação em larga escala, de diferentes maneiras para 'suturar' a falta que constitui o sujeito" (NUNES, 2012, p.33). No entanto, será que a relação de noticiar e poder (dizer) se modifica em função do digital?

\section{Do papel para a tela: o jornalismo (no) digital}

A partir dos anos 80 do século XX, com a popularização das vendas de computadores pessoais e com o advento da web, os sujeitos "comuns" começam a ter acesso à Rede e a produzir conteúdo nela. A máquina, antes restrita ao uso militar ou à realizaçáo de cálculos matemáticos, sem interface nem teclas, ganha novas funçóes e passa a atuar em peso na sociedade contemporânea, re-significando muitos de nossos hábitos e práticas cotidianas. Não só os "sujeitos do cotidiano", mas as próprias instituições foram e são afetadas pelo digital, como podemos observar na imprensa.

Para Dias (2018, p. 27), "é preciso compreender a exterioridade constitutiva do discurso digital, as relaçôes e meios de produção capitalista, os processos da constituiçãao dos sentidos e suas condiçóes de produção, mas também a formulação e a circulação desse discurso". Assim, uma pergunta mobilizadora que nos afronta é: como a instituição jornalística, tomando o digital como uma "condição político-ideológica do discurso", como nos ensina Dias (2018), pela circulação, formula o texto jornalístico?

Um primeiro ponto a ser ressaltado diz respeito à evidência de que os jornais tiveram que se adequar à inovação da internet. Desse modo, podemos problematizar que os "jornais de referência” e de renome possuem ou uma versão digital ou, ao menos, uma página para divulgação de notícias em alguma rede social ou estabelecem, na publicidade, uma relação entre a notícia e o uso de smartphones como meio de acesso à informação.

A instituição jornalística foi convocada a fazer parte do meio digital, e isso trouxe consequências para sua prática. Uma primeira implicação é de caráter espaço-temporal. A demanda por informaçóes em ritmo constante e 
veloz e em quantidades gigantescas é uma característica marcante do jornalismo digital e uma consequência do "estar o tempo todo conectado", que ecoa como lema do ciberespaço.

Como afirma Dias (2004), o ciberespaço é um "transbordamento" do espaço físico, tal como o conhecemos, regido pela necessidade de atualização, em que o tempo se fragmenta em mil pedaços (bits). Para a autora (2004, p. 53), o computador invade "as esferas que sustentam o pensamento humano", e, nesse sentido, "é preciso redefinir a percepção de realidade que nos cerca e entender como o sujeito atua nessa realidade". Também para Levy (1999, p. 27), o tempo é uma questão central quando pensamos o funcionamento do ciberespaço, em que a velocidade de transformação é a única constante.

Quando observamos o funcionamento do jornal, nos seguimentos impresso e on-line (digital), notamos uma distensão temporal entre o tempo daquele e o tempo deste. O jornal impresso, de um grupo jornalístico de publicação diária, tem uma edição por dia, lançada ao público logo nas primeiras horas da manhã, discorrendo sobre aquilo que ocorreu no dia anterior. No jornal em sua versão digital, notícias são atualizadas a todo momento, de forma que o leitor não precisa esperar até o dia seguinte para saber de algo que aconteceu naquele mesmo dia, poucas horas ou mesmo minutos atrás. O que temos, então, são diferentes momentos de enunciação, em que a enunciação no digital se mostra mais veloz, e a necessidade por informaçóes sempre mais veloz.

Isso retoma o que dissemos sobre a noção de informação, agora intensificada pela temporalidade do ciberespaço, reforçando ainda mais a relação excesso-falta e "a concepção de que o sujeito estaria ultrapassado, a não ser que se informasse continuamente das novidades que nem sempre são novidades, mas que são simuladas como se fossem" (NUNES, 2013, p. 43). Outro detalhe interessante, consequência desse descompasso entre tempos de enunciação do jornal impresso e do jornal digital, é que nem tudo o que se publica neste último comparecerá naquele no dia seguinte, o que também ratifica o imaginário de que há mais informação disponível no digital, tornado a melhor opção para se "informar" sempre e sobre "tudo".

Outra implicação que o digital acarreta sobre a atividade jornalística tem a ver com o próprio suporte e com a materialidade que o especifica. O layout, por exemplo, da versão on-line é geralmente muito semelhante ao da impressa, 
mantendo a mesma notícia principal em destaque, os mesmos títulos e leads para os textos, as mesmas imagens etc. Contudo, a técnica digital oferece condiçôes para que seja possível que se adicione mais de uma foto a uma reportagem, criando um pequeno álbum, por exemplo. Além disso, por meio de links, é possível ter acesso a outros textos publicados, por meio de expressóes-chave, o que constitui um grande hipertexto de notícias, em que itens "subterrâneos" conectariam ad infinitum um texto ao outro. Esses e outros funcionamentos do jornal digital (como publicidades que permitem a realização de compras com um simples "clique") apontam para a produção de um efeito de completude para o sujeito que incide sobre o efeito de completude da informação articulada tanto no discurso jornalístico quanto no discurso sobre as novas tecnologias.

De um ponto de vista discursivo, as tecnologias digitais sustentam-se na pretensa objetividade da máquina e no seu caráter "infalível”, em que o equívoco não seria possível (o sem-sentido), o que apaga a historicidade do sentido. Segundo Dias (2018), as ferramentas digitais atuam na possibilidade de pensar o "sem limites, sem fronteira, sem castração simbólica" (DIAS, 2018, p. 58), ou seja, na des-simbolizaçâo do sujeito. Livre para bem fazer/dizer o que quiser, o sujeito vê-se diante da oportunidade de formular e fazer circular os sentidos que deseja. Ele, agora, pelo aparato digital, pode produzir notícias, como em um "jornalismo alternativo" (um jornalismo outro).

O termo "alternativo" gera controvérsia por suscitar um sentido negativo, desviado. Contudo, quando falamos de um “jornalismo alternativo”, encaramo-lo também como aquele que surge de outro ponto de vista, como outra versão possível. Diante de um mesmo fato, diferentes versóes buscam distintos pontos de estabilizaçáo e produzem outros sentidos. Na Rede, o sujeito encontra espaço para ser autor e fazer circular seus sentidos. De leitor/ouvinte da palavra do jornal, pelo digital, o sujeito ordinário tem o poder de dizer.

Por outro lado, encontramos um problema quando o "jornalismo alternativo" não apenas formula um texto diferente daquele da mídia de referência, mas, sentindo-se livre das amarras da realidade no espaço virtual, cria e divulga um "fato alternativo", ou, ainda, uma notícia falsa. O que compreendemos disso é que a linguagem não está ali somente produzindo um sentido para um fato, mas construindo o "fato", ou melhor, a sua narrativa. Diante de e articulada a toda essa conjuntura que explicamos, estão as fake news. 


\section{O caso das fake news: uma análise discursiva}

Tratar sobre fake news, de um ponto de vistam discursivo, demanda uma compreensão sobre a relação da linguagem com o mundo, ou melhor, da realidade com as formas de representá-la. Não é nosso interesse aprofundarmo-nos aqui em uma discussão filosófica sobre o que é a verdade. Entretanto, isso pode interessar na medida em que nos deparamos, nas fake news, com tentativas de argumentação e persuasão por meio de textos noticiosos que não condizem com a realidade. Isso produz uma ruptura com o imaginário jornalístico e sua "missão" de informar fatos verídicos. Contudo, as fake news não ignoram tal imaginário de verdade do jornal; pelo contrário, servem-se dele para tentar alcançar seu desejo de verdade, para se fazer crer. Tanto que, náo raro, reproduzem a textualidade da imprensa, no intuito de fingir uma posiçáo jornalística, recuperando as ilusôes de literalidade e de neutralidade que já mencionamos.

Entretanto, não há discurso isento, neutro e pacífico, discurso que não seja determinado por uma formação ideológica. Dito de outra maneira, é necessário ao sujeito ser sujeito de seu discurso e estar sujeito a ele, pelo processo que Pêcheux (1995) chama de interpelação, colocando-se na ordem do discurso, e isso se efetua

[...] pela identificação (do sujeito) com a formação discursiva que o domina (isto é, na qual ele é constituído como sujeito): essa identificação, fundadora de unidade (imaginária) do sujeito, apoia-se no fato de que elementos do interdiscurso [...] são re-inscritos no discurso do próprio sujeito (PÊCHEUX, 1995, p. 163).

O intuito de nossa análise é, assim, relacionar o eixo do intradiscurso (atualidade) com o eixo do interdiscurso (memória), restituindo ao jornal sua espessura e contradição, para então restituir também às fake news sua opacidade. Essa espessura pode ser devolvida ao discurso jornalístico quando pensamos no processo de formulação (intradiscurso) de uma notícia e desmanchamos seus efeitos de objetividade. Tal procedimento pode ser 
efetuado com base no que postula Hernandes (2004), ao diferenciar os três princípios do processo de produção de um texto jornalístico: (1) a pinçagem, ou seja, a escolha da matéria que comparecerá na notícia; neste primeiro momento, fica definido o que o jornal (o jornalista, a equipe editorial etc.) considera importante e/ou relevante noticiar; (2) a (re)montagem da realidade, que fica a encargo da construção do texto escrito ou oral, das imagens, dos sons etc. que serviriam para apresentar a versão daquele jornal sobre o fato noticiado(por isso, diante de um mesmo fato "pinçado", dois jornais podem produzir montagens (versôes) diferentes); e, por fim, (3) o princípio da negação (ou não contradição), que assegura tanto a linearidade quanto a coerência da notícia em uma lógica disjuntiva (“já que é x, não é y”).

Aprofundando um pouco essa definição de Hernandes (2004), diríamos que, na etapa de pinçagem, começa a estabelecer-se a relação de quem diz com o objeto sobre o qual fala, relação esta vinculada à posição que o locutor assume diante do fato. Já aí se relativiza uma prática jornalística neutra, não somente pelo modo de falar sobre algo, mas pela própria visibilidade concedida ao assunto. $\mathrm{O}$ efeito de objetividade continua a ser desfeito se pensarmos ainda no momento de montagem, que chamaremos de formulação.

$\mathrm{Na}$ formulação é que se torna possível notar as relações de poder (dizer), pois, como defende Orlandi (2005), a formulação é o "acontecimento discursivo pelo qual o sujeito articula manifestamente seu dizer" (ORLANDI, 2005, p. 10); é também nesse momento que se estabelece um ponto de tensão com a pinçagem, permitindo a indagação: havia um fato relevante que foi formulado ou um fato formulado que ficou, por isso, relevante? Atua, então, o princípio de negação (não contradição), que atravessa os outros dois e os equilibra, apagando as contradiçôes, apaziguando as dúvidas, tanto pela lógica disjuntiva do "ou x ou y" supracitada quanto pelo efeito de ênfase, que reforça tanto o imaginário do jornalismo-verdade como a naturalidade de o fato ser dito da forma como foi ("x é x porque eu, que sou eu, digo x"). No jornal, há tentativas de abafar o caráter ideológico do sentido. Nas fake news, há tentativas de forjar uma posição jornalística. 


\section{Figura 1}
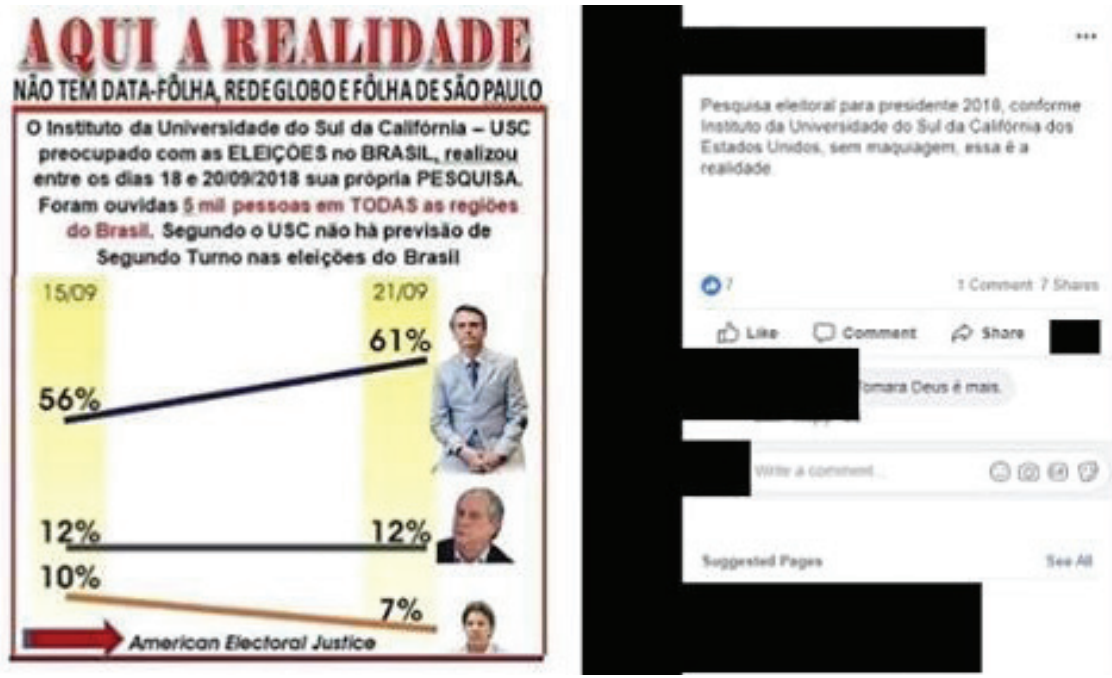

Fonte: https://www.boatos.org/politica/pesquisa-universidade-sul-california.html. Acesso em 10/02/2019.

Na notícia falsa que recortamos para análise, encontramos um texto com um gráfico que teria sido produzido com base em uma pesquisa sobre as eleições do Brasil levada a cabo pela Universidade do Sul da Califórnia, em 2018. Segundo o texto, o resultado das eleições já estava decidido em prol do então candidato Jair Bolsonaro, alegando que não haveria segundo turno. O caráter (efeito) argumentativo visa apresentar a inevitabilidade da vitória de Bolsonaro como obviedade, silenciando as outras possibilidades de voto, como que dizendo para o (e)leitor não "desperdiçar" o voto em candidatos que "nem teriam chance", o que produz efeitos no mundo (nas eleiçôes). E isso se dá pelo efeito de evidência do número, em que as porcentagens de intençóes de voto apontariam, estranhamente/suspeitosamente, para um crescimento significativo da preferência por Bolsonaro no curto período de tempo entre 15 e 21 de setembro. Contraditoriamente, entendemos que o aumento súbito de votos em prol do candidato do PSL, ao mesmo tempo que reforça sua posição de aparente "favorito", acaba por enfraquecer a credibilidade mesma que se deseja instaurar. 
Com efeito, diante do texto em análise, acreditamos que as fake news vão colocar em cena justamente uma tensão entre um imaginário de tecnologia que não falha (solução para todos os problemas) e as falhas/desvios do próprio processo de produção e circulação, sob um efeito da mesma eficácia tecnológica, de uma notícia falsa. Se, segundo Dias (2018, p. 158), “a viralização é o grau máximo dessa eficácia”, é justamente a replicação (o excesso) das fake news que pode estabelecer o conflito: a notícia, na circulação, no compartilhamento, pode vir a produzir sentidos outros, "na medida em que significa por outras relaçóes" (DIAS, 2018, p. 164).

Interessante notar também que os candidatos apresentados não são nomeados, mas apenas representados pelas respectivas imagens, mal cortadas e desproporcionais, que jogam contra a literalidade do numérico, deixando escapar a subjetividade, sempre evasiva nas fake news, ao colocar, por exemplo, a imagem de Bolsonaro com o dobro do tamanho das imagens de Ciro Gomes e Fernando Haddad. A contradição da ideologia faz-se presente pela falha da/ na linguagem, e a posição-sujeito se dá a ver pela "identificação (do sujeito) com a formação discursiva que o domina” (PÊCHEUX, 1995, p. 165), visto que o interdiscurso intervém no discurso do próprio sujeito.

Reafirmando o imaginário da imprensa como "portadora" da verdade, investindo em seu caráter utilitário e transparente, as fake news buscam diferentes formas de validação: por exemplo, a remissão à instituição acadêmica figurada, neste caso, pela University of South California ${ }^{3}$ e a um suposto órgáo eleitoral do governo estadunidense (American Electoral Justice) que, na verdade, não existe (não sob esse nome, pelo menos). A institucionalização funciona aqui como procedimento de atribuição de "real", de "efeito de verdade" à notícia falsa. Por outro lado, o efeito contrário é o de legitimação pelo discurso que vem de fora do país (como se fosse a "REALIDADE") e a consequente rejeição daquilo que se produz no Brasil (Folha de S. Paulo, Rede Globo). Paradoxalmente, recusa-se o jornal ao passo que se deseja ocupar a mesma posição (jornalística).

3 A própria instituição declarou, em nota, que nunca realizou tal pesquisa, conforme lido em https://oglobo.globo.com/fato-ou-fake/e-fake-que-universidade-do-sul-da-california-fez -pesquisa-aponta ndo-que-nao-ha-previsao-de-2-turno-na-eleicao-presidencial-23119228. Acesso em 10/02/2019. 
Novamente, como comentado, como forma de produzir o efeito de verdade, a notícia falsa retoma um ponto de referencialidade seguro relativo à textualização da notícia jornalística (e o imaginário da instituição), apresentando o contexto da suposta pesquisa realizada pela Universidade do Sul da Califórnia, como a data ("entre os dias 18 e 20/09/2018") e os sujeitos envolvidos na pesquisa ("cinco mil pessoas em TODAS as regióes do país”). Mesmo denegrindo a produção jornalística da mídia de referência, as fake news não escapam de uma inscrição em um dado modo de formular a notícia, remetendo ao imaginário do jornal e dos sentidos que ele engendra sobre essa prática.

Contudo, esse texto só "faz sentido" na medida em que circula pelo ambiente digital, de forma que, como visto na imagem da direita, na figura 1, é imprescindível que os sujeitos-usuários (na tensão leitor-autor) se prestem a compartilhar essas "notícias", acrescendo-lhes comentários e direcionando-as para outros usuários da rede social (neste caso, o Facebook), que reagem com likes, comentários e novos compartilhamentos. Acentuando o apelo à credibilidade da notícia em questão, a postagem insiste em dizer que os dados apresentados demonstram "a realidade", sem a manipulação nem a “maquiagem” da Mídia.

\section{Algumas considerações}

Não tivemos pretensão alguma de esgotar as discussóes nem sobre o discurso jornalístico nem sobre sua complicada relação com as fake news, e acreditamos que outros sentidos poderiam ser mobilizados e outras direçóes poderiam ser seguidas. Neste texto, o que buscamos fazer foi mostrar como a ligação do jornalismo com a "verdade" tem seu caráter ideológico muitas vezes apagado, tornando a relação evidente. Silencia-se a disputa pela "verdade", que é produzida como efeito no discurso.

Acrescenta-se a isso as implicaçóes da discursividade digital que afetam não só a relação do sujeito com o conhecimento, mas a própria prática jornalística. Como consequência do acesso "irrestrito" à informação e da descentralização da produção de informação, o sujeito comum passa a poder tomar a palavra jornalística e a formular notícias. Esse processo aponta para o problema talvez não do acesso em si, mas da discursividade mesma que legitima esse acesso. 
A possibilidade (pré-consciente) de escolher a formulação leva o sujeito ao esquecimento número dois (impressão de realidade do pensamento), a tal ponto que se veria livre para apagar as condições históricas de produção do discurso ou outras possibilidades de dizer que foram deixadas de lado em favor dos sentidos que lhe beneficiem, colocando em circulação as fake news. Pela reprodução do mesmo sentido, os meios digitais de comunicação podem cumprir sua função de legitimação do sentido dominante, similar ao que discutimos a respeito da imprensa. Dessa forma, pela dimensão técnica do "excesso ao ponto da perda", característico das práticas discursivas digitais, as fake news aparecem não como novidade (como se não existissem notícias falsas antes da internet), mas como sintoma de uma sociedade profundamente dividida.

\section{Referências}

DIAS, C. P. Análise do discurso digital: Sujeito, espaço, memória e arquivo. Campinas: Pontes, 2018.

. A discursividade da rede (de sentidos): a sala de bate-papo hiv. Tese (Doutorado em Linguística), Universidade Estadual de Campinas, Campinas, 2004.

HERNANDES, N. Análise da edição 1533. In: . A revista Veja e o discurso do emprego na globalização. Salvador: Edufba, 2004, p. 87-140.

LEVY, P. Cibercultura. Tradução de Carlos Irineu da Costa. São Paulo: Ed. 34, 1999.

MARIANI, B. S. C. O comunismo imaginário: práticas discursivas da imprensa sobre o PCB (1922-1989). Tese (Doutorado em Linguística) - Instituto de Estudos da Linguagem, Universidade Estadual de Campinas, Campinas, 1996.

NUNES, S. R.A geometrização do dizer no discurso do infográfico. Tese (Doutorado em Linguística), Universidade Estadual de Campinas, Campinas, 2012.

ORLANDI, E. P. Discurso e texto: formulação e circulação dos sentidos. Campinas: Pontes, 2005.

PÊCHEUX, M. Semântica e discurso: uma crítica a afirmação do óbvio. Tradução de Eni Pulcinelli Orlandi. Campinas: Unicamp, 1995. 


\title{
JOURNALISM IN THE DIGITAL ERA AND FAKE NEWS
}

\begin{abstract}
In this article, we present a reflection on journalism and fake news practices, linking them to the digital apparatus, in order to discuss the effects of truth produced in discourse. Based on the theoretical and methodological procedures of the French Analysis of Discourse, it was possible to understand better the relation between the subject and the production of fake news through the digital technique discursivity.
\end{abstract}

KEYWORDS: press; digital journalism; fake news. 